\title{
Integrated spatial and energy planning: a means to reach sustainable development goals
}

\section{Gernot Stoeglehner ${ }^{1}$}

Published online: 13 February 2020

(c) The Author(s) 2020

\begin{abstract}
Climate protection targets call for a transition towards sustainable energy systems based on energy saving, more energy efficiency and renewable energy sources. The options for energy strategies are highly shaped by local and regional spatial contexts like urban, suburban or rural areas or small towns embedded in rural or suburban areas. Both energy efficiency and renewable energy potentials are determined by these spatial contexts, so taking them into consideration leads to more realistic energy strategies. Therefore, integrated spatial and energy planning is an important field of action in order to reach Sustainable Development Goal 7-clean and affordable energy. In this conceptual paper, the ideas and basic principles of integrated spatial and energy planning are introduced, and it is discussed, how this concept might help not only to reach the energy transition but might also support further sustainable development goals. The paper is based on research results gained from Austrian experiences.
\end{abstract}

Keywords Spatial planning · Energy strategies - Sustainable development goals · Energy transition $\cdot$ Integrated spatial and energy planning $\cdot$ Sustainability

\section{JEL Classification R1}

\section{Introduction}

The Sustainable Development Goals (SDGs) as agreed in the 2015 UN Sustainable Development Summit in New York set a global framework for the transition towards sustainable development. The concept is based on 17 goals with 169 targets with a time horizon 2030, as well as a list of 232 indicators to monitor the progress towards

Gernot Stoeglehner

gernot.stoeglehner@boku.ac.at

1 Department of Landscape, Spatial and Infrastructure Sciences, Institute of Spatial Planning, Environmental Planning and Land Rearrangement, University of Natural Resources and Life Sciences Vienna, Peter Jordan Straße 82, 1190 Vienna, Austria 
achieving the SDGs. The SDG 7 calls for clean and affordable energy. Looking at the specific targets until 2030, (1) universal access to clean, affordable, reliable, sustainable and modern energy services shall be granted to all people, (2) the share of renewable energy shall be substantially increased on a global scale, (3) the global rate of energy efficiency improvements shall be doubled, (4) investments in energy infrastructure and clean energy technology shall be promoted, and (5) energy infrastructure shall be modernized, inter alia, to provide sustainable energy services in developing countries (United Nations n.y.). To fulfill the targets of the Paris Agreement, the use of fossil energy sources should be severely reduced or stopped by 2050 especially in industrialized countries (Intergovernmental Panel on Climate Change 2018). Therefore, the European Union defined a roadmap for the energy transition to reach a reduction in greenhouse gas emissions of around $90 \%$ till 2050 (European Commission 2011, 2018).

To reach these ambitious climate protection targets, a substantial re-organization not only of the energy systems but also of the human activities leading to energy demand are necessary to reach substantial energy saving. At the moment, most scenarios provided to reach the energy transition are not only based on renewable energy provision, but also on substantial energy savings of households, companies and public entities (see e.g. China National Renewable Energy Centre et al. n.y.; Martinot and McDoom 2000; European Commission 2011, 2018). The possibilities to save energy and to utilize renewable energy sources is dependent on different influencing factors like (a) different policies like agricultural, economic, environmental or housing policies, (b) economic practices of economic sectors or individual companies, (c) individual lifestyles, (d) locally or regionally available renewable resources, (e) availability of technologies, (f) the base values of societies as well as (g) the spatial structures in certain areas (Stoeglehner et al. 2014).

To address the interrelations between spatial structures and the possibilities to shape the energy transition, the concept of integrated spatial and energy planning (ISEP) was elaborated in Austria in the last decade. This concept starts to influence policy making on all levels of government - from national to regional and municipal level. The author of this article and his team contributed major research findings to conceptualize ISEP, developed planning methods and planning tools. Furthermore, the author consulted policy makers in shaping spatial planning decisions in support of the energy transition to facilitate bringing scientific knowledge into action in Austria. In this article, these experiences of the last ten years of work are summarized in chapters 2 and 3 based on own published work, so that the ideas of ISEP can be introduced to the community of evolutionary economists, which is the first purpose of this article. Second, the article aims at contextualizing ISEP with the SDGs based on an analysis and interpretation of the interrelations between the guiding principles of ISEP and the SDGs (Chapter 4). The article corresponds to an invited presentation that was held at the 7th international symposium 2018: "Let's Work Together Toward Achieving Sustainable Development Goals" organized by the Graduate School of Advanced Integrated Studies in Human Survivability (GSAIS) at Kyoto University. 


\section{The concept of integrated spatial and energy planning}

In Austria, the spatial planning system is highly formalized and regulated in Spatial Planning Acts on the level of the nine provinces. Therefore, the planning systems consist of provincial and regional spatial programs as well as municipal spatial plans which form a hierarchy of normally six spatial programs and plans: (a) the provincial development strategies, regional and sectoral programs that comprise either the whole provincial territory or certain regions, and (b) municipal spatial plans, normally the local development strategies, land use plans and building schemes. These plans address environmental issues and open space protection, social and cultural topics as well as economic development and infrastructure provision (Stoeglehner 2019). The concept of ISEP is embedded in this formalized spatial planning system as an integral part that addresses the spatial dimensions of energy demand and energy supply in a holistic way.

The planning principles of ISEP introduced in the next paragraphs converge with ideas from planning visions related to sustainable spatial development, like Ecocities (Newman and Jennings 2008; Register 2002), New Urbanism (CNU 2001), European Cities of Tomorrow (European Union 2011), and regional scale planning visions like transit-oriented development (Dittmar and Ohland 2004) or decentralized concentration (Motzkus 2002). These planning visions have certain planning principles in common, which are striving for compactness, promoting sustainable transport (walking, cycling, public transport), pursue an adequate density, implement mixed land uses and diversity, support passive solar design, and aim at green infrastructure supply (Jabareen 2006). All these planning principles are, inter alia, justified with a higher quality of life and well-being for the residents, a better organization of daily life, more open and green spaces, and a reduction of motorized transport as well as more resource and energy efficiency. The ISEP concept as presented here deals with the potentials and options to support climate protection and the energy transition with means of spatial planning, so it contextualizes spatial planning in the set of policies discussed to solve the climate crisis (Stoeglehner et al. 2016). For instance, a system analysis (Stoeglehner et al. 2011) showed that these planning principles for energy efficient spatial structures are crucial to provide frameworks for energy efficiency and sustainable energy supply. Also when the scale is changed to specific elements of energy supplies like grid bound energy systems, these planning principles support spatial preconditions for an efficient and sustainable technology application (Zach et al. 2019).

Figure 1 shows how the spatial dimensions of energy supply and energy demand can be described, and how they are linked with each other by the concept of energy-efficient spatial structures. The spatial dimension of the energy demand aims at energy-efficient spatial structures that are designed following the spatial planning principles of mixed-use areas, (moderate) density of population and workforce, nearness and compactness. The spatial dimensions of energy supply can be, on the one hand, identified with classical spatial planning tasks such as securing of sites and mitigation of land use conflicts, on the other hand with 


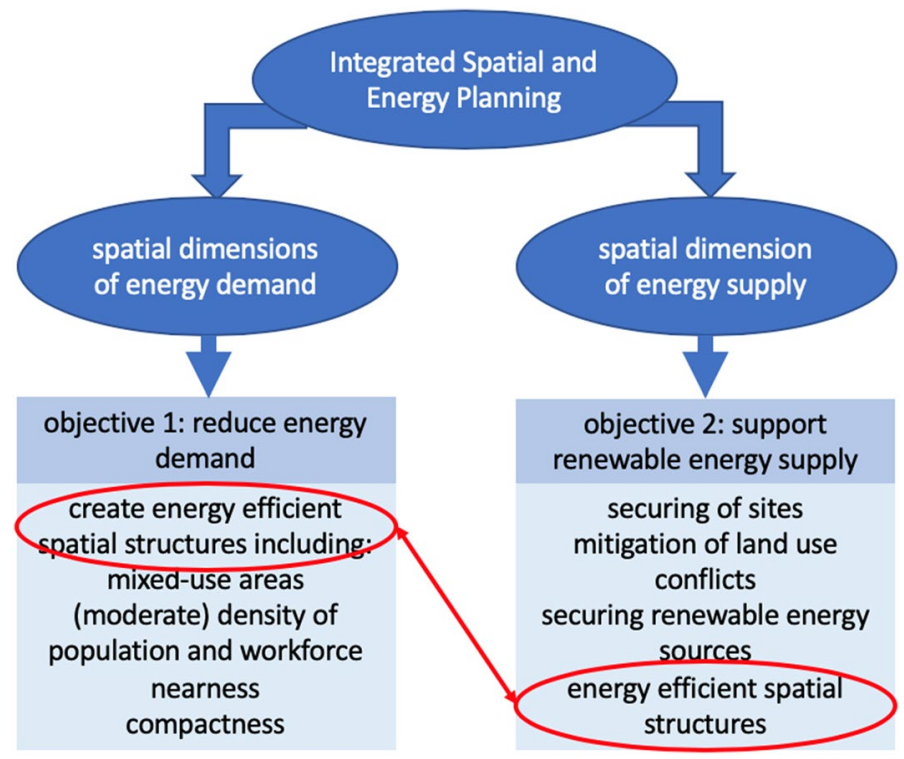

Fig. 1 The concept of ISEP (after Stoeglehner et al. 2014)

the new task of securing renewable energy sources. Therefore, larger areas not used for building land shall be kept as open space to be able to build wind parks or secure agricultural land to provide both for sufficient food production and for the production of industrial raw materials and energy. Furthermore, energy-efficient spatial structures offer more room to maneuver for the implementation of renewable energy supplies, so they connect the spatial dimensions of demand and supply. First, they leave more space open that can be used for renewable energy supply, and they can be supplied with grid-bound renewable energy more easily. Density guarantees for the efficiency of grid-bound energy systems, mix of functions for a better relation of peak loads and base loads (Stoeglehner et al. 2016). In Austrian climatic conditions, energy-efficient spatial structures can provide for 4500-5500 full load hours for district heating systems whereas residential areas can cater for 1500-2200 full load hours (Neugebauer et al. 2015). These favorable conditions structurally support promising strategies to tackle new challenges for the energy transition, such as integrating volatile renewable energy sources into the energy system by the power to heat/cold solutions so that load shifts and sector coupling ${ }^{1}$ can be efficiently organized no matter which specific technology will be applied (Lichtenwoehrer et al. 2019).

Looking at the spatial structures on a larger scale, the spatial archetypes urban, rural, suburban areas as well as rural or suburban small towns highly influence the

\footnotetext{
1 Sector coupling connects different energy end-uses and supply sectors with each other. In doing so, energy systems shall become more efficient, flexible and reliable. Furthermore, decarbonization of the energy system shall be supported (van Nuffel et al. 2018).
} 
possibilities to shape the energy transition (Stoeglehner et al. 2011, 2016): urban centers are characterized by a high energy demand and density with a limited number of renewable energy sources at hand. Normally, urban centers have a large energetic and resource hinterland that is needed to support the urban areas. On the other hand, urban centers have very good preconditions for energy and resource efficiency because of energy-efficient settlement structures as described above. Therefore, the energy transition in cities very likely will have to be mainly based on efficiency strategies with a certain domestic energy generation potential from sources such as solar, waste incineration, geothermal, wastewater energy. On the other side of the bandwidth rural areas have lower energy efficiency potentials because of low densities and a reduced mix of spatial functions. Yet, they have more possibilities to tap renewable energy sources and can provide energy also for other spatial archetypes.

Small towns have similar conditions concerning energy-efficient spatial structures as urban centers, but are more closely integrated with surrounding rural (or suburban areas) so that they have better access to renewable energy sources, including biomass, wind, hydropower and solar. Therefore, they might be developed to energy and resource nodes of a decentralized industrial society. Suburban areas are somewhere in-between, the energy efficiency of spatial structures is very likely relatively low because of large areas of building land with low densities, a reduced possibility to generate renewable energy as the fabric of building and agricultural land might cause land-use conflicts so that e.g. the siting of wind parks might be impossible or difficult. The energy transition might very likely call for a closer cooperation between the spatial archetypes, which might also be an important factor for regional development. Rural areas might utilize the energy transition to gain new economic opportunities as, finally, all energy that cannot be provided in urban and suburban areas or in the small towns on site, has to be generated in rural areas. For further information on these issues, please refer to Stoeglehner et al. (2016).

In ISEP strategies the following issues should be raised based on sound baselines surveys, exhausting the specific strengths of the respective spatial archetypes: (1) realistic targets concerning energy savings in relation to the existing building stock, infrastructures, mobility patterns as well as economic structures of municipalities and regions; (2) energy generation potentials of locally or regionally available renewable energy sources, taking environmental capacity limits, the closing of regional resource flows (e.g. nutrient flows in case of biomass utilization) and social acceptance of potential installations into account; (3) the definition of shares of renewable energy sources as input to the energy systems, that take both the local and regional generation potentials, traded energy as well as conflicting land-use demands (e.g. food versus fuel, fuel versus fibre, etc.,) into account; (4) the selection of energy technologies and their sites to guarantee a diverse, reliable, secure and economically feasible energy supply in respective technology networks (Stoeglehner et al. 2016). 


\section{Approaches for integrated spatial and energy planning}

To facilitate ISEP, a multitude of approaches is necessary, that combines methodological developments, the provision of databases with regulatory and financial instruments, public investments as well as awareness raising, research and (further) education. In this section some examples are introduced that are based on own research: (1) the ISEP strategy Styria as an example of policy implementation, (2) spatio-temporal modelling as an example of tool development for the integrating of different energy technologies in certain spatial structures, and (2) wastewater energy use as an example for defining potentials, objectives and measures for a certain technology from an ISEP point of view.

\subsection{ISEP strategy Styria}

The first example is a strategy to implement ISEP in a whole Austrian Province, Styria (Abart-Heriszt and Stoeglehner 2019). The whole initiative for ISEP is based on the Styrian Spatial Planning Act, where municipalities are entitled to adopt concepts of ISEP as part of their local development strategies striving for energy efficiency and an increase in renewable energy provision. The ISEP strategy presented here aims to bring this legal provision to life.

The steps comprise methodological developments and their application as follows:

- detailed energy and $\mathrm{CO}_{2}$ emission balances for all 287 municipalities of the province as baseline for energy and climate change mitigation policies taking local spatial patterns, population and economic structures as well as mobility patterns into account ${ }^{2}$;

- suitability areas for district heating as well as environmentally friendly mobility, which are representations of energy-efficient spatial structures;

- a guidance on how these results can be utilized in planning process of statutory spatial planning, e.g. by defining realistic prioritizing further settlement developments in the suitability areas;

- a training program for spatial planners and municipalities as well as by a subsidy program for municipalities that conduct such concepts of ISEP.

The $\mathrm{CO}_{2}$ emission balances were distributed to the municipalities and the suitability areas were implemented in the Provincial geographical information system in April 2018, so that all municipalities have free open access to their respective planning information. Since the public start of the program in March 2018 and the presentation of the guidance, staff members of all the spatial planning offices who operate in Styria could be trained, about one-third of the municipalities participated

\footnotetext{
2 Starting from January 2020, the energy and $\mathrm{CO}_{2}$ emission balances are available for all Austrian municipalities at https://www.energiemosaik.at (Abart-Heriszt et al. 2019).
} 
in trainings, and around $10 \%$ of the municipalities were granted the subsidy for ISEP concepts. Already two municipalities could integrate an ISEP concept within their legally binding spatial development strategy.

\subsection{Spatio-temporal modelling}

Nowadays, a multitude of planning tools on all spatial levels is available to support planners and decision makers in strategy making for the energy transition (Stoeglehner et al. 2014). One important approach is spatio-temporal modelling (Ramirez Camargo et al. 2015; Ramirez Camargo and Stoeglehner 2018) based on geographical information systems (GIS). In the method proposed, detailed data about buildings and their energy demand (for room heating and electricity) as well as local energy supply potentials (e.g. building-integrated photovoltaics (PV), solar thermal, wastewater energy, biomass) are estimated and modelled not only in a high spatial resolution taking grid-bound energy provision (i.e. district heating, electricity grids) into account, but also in a high temporal resolution of 15 min for electricity and $1 \mathrm{~h}$ for heating. For local volatile energy provision like PV, meteorological and elevation models are used to estimate the energy demand in 15 min resolution taking the distributed yearly energy provision potentials into account. In this way, the relation of energy demand and local energy provision can be modelled for each point of space and time of a year, so that grid and/or storage capacities can be determined (for more information, see Ramirez Camargo and Stoeglehner 2018).

Therefore, with this model can be examined to which extent surplus electricity is available to run heat pumps, or load electric car batteries. In this way, the spatiotemporal model is especially valuable to support coupling of different infrastructures and energy sectors to design more energy efficient and primary energy saving energy systems. This system integration or coupling of infrastructures, technologies, services, electricity, heat/cold as well as electric mobility is an important field of action to increase the flexibility of the electricity demand so that volatile renewable energy sources can be dealt with in the energy system, to use efficient and affordable energy storage and to apply elements of coupling like combined heat and power, power to heat/cold, power to gas as well as power to chemicals (Federal Ministry for Sustainability and Tourism and Federal Ministry for Transport, Innovation and Technology 2018). An example for coupling different energy sectors and infrastructure systems is discussed in the next section.

\subsection{Wastewater energy use}

A promising example of sector coupling is wastewater energy as proposed by Neugebauer et al. (2015): In this concept, energy is extracted at the discharge of wastewater treatment plants by heat exchangers and heat pumps. With this energy district heating grids can be run at different temperature levels, e.g. low energy grids with decentralized heat pumps, or classical energy grids with temperature levels close to $100{ }^{\circ} \mathrm{C}$, wherein a bivalent system the higher degrees are provided by an additional heat source such as digester gas or wood chips. In this way, coupling of wastewater 
infrastructure, district heating supply, and electricity (power to heat/cold) can be implemented. If this heat source is used for agricultural production in greenhouses, e.g. the return flow after the heat is delivered to settlements, the system integration can be expanded to the food system.

An important precondition is the spatial fabric and the siting of potential energy consumers and the wastewater treatment plant, an issue of spatial planning. Yet, not only the spatial preconditions or the feasibility of technologies are important success factor for wastewater energy utilization, but also the timely inclusion of all relevant stakeholders in participatory planning processes (Kretschmer et al. 2018). Spatial planning can also provide planning processes to facilitate this participation and the negotiation processes in society to develop, adopt and implement planning strategies for the energy transition (Stoeglehner et al. 2014). This is also important when concepts like "prosumers"- persons and companies who act as consumers and producers of energy - should be widely applied, e.g. in district heating grids (see e.g. Lichtenegger et al. 2017).

\subsection{Resumé and outlook}

Summing up, the spatial planning processes may not only be used for awareness raising and system integration of different energy sources as well as the joint development of grid-bound energy supply networks and prosumer demand and supply, they can also be used to negotiate land-use conflicts around renewable energy generation facilities and to choose sites that do not only provide adequate renewable energy generation potentials, but that are suitable with respect to the environmental impacts and social acceptance. Especially strategic environmental impact assessment for spatial plans and programs can serve as platform for impact appraisal and the selection of sustainable, environmentally friendly planning alternatives concerning the choice of energy technologies and their sites, size of projects etc.

\section{Interrelations between integrated spatial and energy planning and sustainable development goals}

First of all, the idea of ISEP addresses SDG7-affordable, reliable and modern energy services (United Nations n.y.), as already stated in the introduction. With the holistic approach presented in this article, structural energy efficiency of spatial patterns beyond the single energy-consuming process (e.g. heating of buildings, industrial process energy, mobility) can be achieved, which corresponds to target 7.1 and supports energy efficiency strategies especially when sector coupling should be addressed according to target 7.3. Furthermore, the share of renewable energy according to target 7.2 can only be substantially increased, if areas for renewable resource production and sites for energy generation can be efficiently secured, which is a further task of ISEP in all spatial archetypes. As ISEP approaches, as presented in chapter 3, are designed to find the most suitable areas and sites for energy infrastructure, the approach is also relevant to promote feasible investments and clean 
energy technologies according to target 7.a and 7.b including developing countries so that spatial structures and energy infrastructure can be jointly developed and financial flows can be targeted to projects that are most beneficial for the respective populations. In these ways, ISEP is suitable to address all targets related to SDG7.

As energy supply is one of the basic infrastructures of societies, supporting SDG7 with ISEP more or less affects all other SDGs directly or indirectly. This is especially true because the design principles of energy-efficient spatial structures as presented above, are also well known from different urban planning visions that deal with sustainable spatial development [for an analysis of design principles for sustainable urban planning see Jabareen (2006)]. A brief look to the further SDGs on the level of targets reveals the following direct interrelations with ISEP:

- SDG1: poverty reduction is associated with equal access to economic resources and basic services according to target 1.4 , and target 1.2 calls to end poverty in all dimensions (United Nations n.y.). Especially the utilization of locally and regionally available renewable energy resources according to ISEP-strategies might not only generate economic income, it might also be more affordable so that it has the potential to reduce energy poverty (see e.g. Bonatz et al. 2019).

- SDG6: in target 6.6, the protection and restoration of water-related ecosystems is called for (United Nations n.y.). In the case of hydropower use this target can be counteracted by negative environmental impacts (Dorber et al. 2019). This conflict can be resolved in ISEP-strategies by defining the shares of renewables in the energy mix of a certain area, protecting vulnerable ecosystems from energy generation facilities.

- SDG8: ISEP-strategies might help to increase resource efficiency and to support decoupling of economic growth, energy demand and environmental degradation (target 8.4), inter alia by supporting spatial structures that allow for sector coupling and cascadic use of energy e.g. of different temperature levels, so that the exergy can be optimized. Renewable energy generation might effectively create new jobs, especially green jobs (target 8.5) (Dvořák et al. 2017; Bonatz et al. 2019; United Nations n.y.) and has the potential to unfold economic activity in disadvantaged rural areas (Benedek et al. 2018).

- SDG9: Especially targets 9.1 (quality, reliable, sustainable and resilient infrastructure) and 9.2 (inclusive and sustainable industrialization) (United Nations n.y.) can be supported by ISEP-strategies directly and indirectly, as energy supply is a basic infrastructure, and diverse renewable energy systems might be more sustainable and resilient (Erker et al. 2017). Furthermore, the renewable energy sector might spur future-oriented industrial sectors for the production of energy generation, storage and distribution facilities.

- SDG11: As the concept of ISEP is strongly linked to sustainable urban planning both content wise and related to planning processes, there is-because of the concept of energy-efficient spatial structures-a strong link to targets 11.2 - sustainable transport, 11.3 - sustainable urban planning and participation, and 11.6-reducing the environmental impact. Target 11.a-supporting links between urban, peri-urban and rural areas (United Nations n.y.) can be enhanced by the cooperation between spatial archetypes as laid out in Chapter 2. There- 
fore, in Austrian debates about ISEP it is often stated that ISEP might be beneficial to find new arguments for sustainable spatial planning (Stoeglehner et al. 2014), as the recent spatial developments are often in conflict with sustainability (Stoeglehner 2019).

- SDG12: ISEP supports efficient energy consumption, renewable energy generation, as well as the idea of decentralized energy generation as well as incorporating energy prosumers in the energy system, so that target 12.2 (sustainable management and efficient use of natural resources) (United Nations n.y.) can be facilitated by taking the spatial patterns of consumption and production into account, as laid out in the previous chapters.

- SDG13: Climate mitigation policies are a major driver to implement ISEP, therefore, especially the implementation of target 13.2 (integration of climate change measures into national policies, strategies and planning) (United Nations n.y.) can be supported by breaking down such strategies on the regional and local level, considering the respective spatial context for concrete objectives and action planning.

- SDG15: Even though energy efficient, renewable energy supplies have a significant potential to reduce overall environmental pressures of the energy systems (Narodoslawsky and Stoeglehner 2010), energy generation, storage and distribution facilities might have significant negative impacts on the environment. ISEPapproaches as described above can integrate such considerations in energy strategy formation in early stages, so that especially targets $15.1,15.2,15.4$ and 15.5 that address the conservation, restoration and sustainable use of different ecosystems (United Nations n.y.) can be supported by ISEP.

As can be seen from this analysis, that interprets the SDGs in relation to the targets and their indicators, direct links between ISEP and 22 targets related to 9 SDGs can be found. Yet, I argue that at least links to two more SDGs can be established: Concerning SDG2 (United Nations n.y.), food versus fuel (and fibre) are important discourses (Stoeglehner and Narodoslawsky 2009). The definition of renewable energy supply potentials in ISEP-strategies can take these conflicts into account by protecting agricultural land and forests from the construction of energy generation, distribution and storage facilities. Furthermore, the amount of energy crops that can be used (or should not be used) can be reflected in the choice of energy sources and energy technologies. Furthermore, strong links can be established to SDG3 (United Nations n.y.): energy efficient spatial structures support active mobility, especially walking and biking. Therefore, ISEP-strategies related to reducing energy demand of mobility might also lead to healthier lives, as debates about active mobility and health promotion via urban planning show (Baumgart 2017).

\section{Conclusions}

The challenges of the energy transition to meet SDG7 need spatial analyses and spatial planning to energy-efficient spatial structures, to support area-based integration of renewable energies and to reach sector coupling not only between different parts 
of the energy system but also by connecting different infrastructure systems. This is an important spatial precondition to implement load shifts. To support this kind of strategies, there is not only a need for spatially and temporally highly resoluted decision making models, but also for integrated policy making including integrated spatial and energy planning, financial steering instruments like subsidies and taxes, awareness raising of the general public, public investments as well as education and training of experts by further education offers for spatial planners and energy planners.

Even though the legal implementation of ISEP results is based on the Austrian context, the ISEP general outline is related to the system interrelations between spatial structures and sustainable energy supplies, and to the planning processes and methodologies to make them operational in urban and regional planning. Therefore, ISEP thinking is transferrable to countries all over the world, even though specific spatial structures or the respective renewable resource base, or stakeholder constellations might be different. As discussed above, ISEP thinking is suitable to fulfil SDG7 and different aspects of further SDGs in different country-specific contexts.

If energy-efficient spatial structures are promoted, this largely conforms with planning principles for sustainable spatial development, especially mix of functions including open space and green infrastructure, moderate density, nearness allowing for transport systems not dependent on individual car transport, and compactness. In this way, win-win situations with other SDGs can be reached that support well-being and quality of life for the population. Engaging in integrated spatial and energy planning might, therefore, be not only beneficial for decision makers and planners on all governmental levels but also rewarding for research and education.

Acknowledgements Open access funding provided by University of Natural Resources and Life Sciences Vienna (BOKU). The author thanks all staff members of the Institute of Spatial Planning, Environmental Planning and Land Rearrangement at the University of Natural Resources and Life Sciences Vienna who engaged themselves in research projects, doctoral theses and publications related to ISEP. Furthermore, I thank the numerous fellow researchers, stakeholders and funders of the research projects that formed the basis of this article.

\section{Compliance with ethical standards}

Conflict of interest The author declares no conflicts of interest.

Ethical approval This article does not contain any studies with human participants or animals performed by the author.

Open Access This article is licensed under a Creative Commons Attribution 4.0 International License, which permits use, sharing, adaptation, distribution and reproduction in any medium or format, as long as you give appropriate credit to the original author(s) and the source, provide a link to the Creative Commons licence, and indicate if changes were made. The images or other third party material in this article are included in the article's Creative Commons licence, unless indicated otherwise in a credit line to the material. If material is not included in the article's Creative Commons licence and your intended use is not permitted by statutory regulation or exceeds the permitted use, you will need to obtain permission directly from the copyright holder. To view a copy of this licence, visit http://creativecommons.org/licen ses/by/4.0/. 


\section{References}

Abart-Heriszt L, Stoeglehner G (2019) Das Sachbereichskonzept Energie: Ein Beitrag zum Örtlichen Entwicklungskonzept. Leitfaden. Version 2.0. im Auftrag der Steiermärkischen Landesregierung, Abteilung 13, 15 und 17

Abart-Heriszt L, Erker S, Stoeglehner G (2019) The Energy Mosaic Austria-a Nationwide energy and greenhouse gas inventory on municipal level as action field of integrated spatial and energy planning. Energies 12(16):3065. https://doi.org/10.3390/en12163065

Baumgart S (2017) Public health and urban planning: challenging options for well-being: experiences from Germany. In: Phillips R, Wong C (eds) Handbook of community well-being research, vol 126. Springer, Dordrecht, pp 221-237

Benedek J, Sebestyén T-T, Bartók B (2018) Evaluation of renewable energy sources in peripheral areas and renewable energy-based rural development. Renew Sustain Energy Rev 90:516-535. https://doi. org/10.1016/j.rser.2018.03.020

Bonatz N, Guo R, Wu W, Liu L (2019) A comparative study of the interlinkages between energy poverty and low carbon development in China and Germany by developing an energy poverty index. Energy Build 183:817-831. https://doi.org/10.1016/j.enbuild.2018.09.042

China National Renewable Energy Centre, The Danish Energy Agency, Energinet in Denmark, GIZ, German Energy Agency, Agora Energiewende in Germany, US National Renewable (n.y.) Energy Transition Trends 2018: China, Europe, USA. https://shop.dena.de/fileadmin/denashop/media/Downl oads_Dateien/esd/9256_Energy_Transition_Trends_2018_-_China_Europe_USA.pdf. Accessed 15 March 2019

CNU (2001) Congress of the New Urbanism: The Charter of the New Urbanism. https:/www.cnu.org/ sites/default/files/charter_english.pdf. Accessed 10 Oct 2019

Dittmar H, Ohland G (2004) The new transit town: best practices in transit-oriented development. Island Press, Washington DC

Dorber M, Mattson KR, Sandlund OT, May R, Verones F (2019) Quantifying net water consumption of Norwegian hydropower reservoirs and related aquatic biodiversity impacts in Life Cycle Assessment. Environ Impact Assess Rev 76:36-46. https://doi.org/10.1016/j.eiar.2018.12.002

Dvořák P, Martinát S, van der Horst D, Frantál B, Turečková K (2017) Renewable energy investment and job creation; a cross-sectoral assessment for the Czech Republic with reference to EU benchmarks. Renew Sustain Energy Rev 69:360-368. https://doi.org/10.1016/j.rser.2016.11.158

Erker S, Stangl R, Stoeglehner G (2017) Resilience in the light of energy crises-part I: a framework to conceptualise regional energy resilience. J Clean Prod 164:420-433. https://doi.org/10.1016/j.jclep ro.2017.06.163

European Commission (2011) Communication from the Commission to the European Parliament, the Council, the European Economic and Social Committee and the Committee of the Regions: A Roadmap for moving to a competitive low carbon economy in 2050. COM(2011) 112 final. https:// eur-lex.europa.eu/legal-content/EN/TXT/PDF/?uri=CELEX:52011DC0112\&from=EN. Accessed 15 March 2019

European Commission (2018) Communication from the Commission to the European Parliament, the European Council, the Council, the European Economic and Social Committee, the Committee of the Regions and the European Investment Bank: A Clean Planet for all A European strategic long-term vision for a prosperous, modern, competitive and climate neutral economy. COM(2018) 773 final. https://eur-lex.europa.eu/legal-content/EN/TXT/PDF/?uri=CELEX:52018DC077 $3 \&$ from $=$ EN. Accessed 15 March 2019

European Union (2011) Cities of Tomorrow. Challenges, visions, ways forward. https://ec.europa.eu/regio nal_policy/sources/docgener/studies/pdf/citiesoftomorrow/citiesoftomorrow_final.pdf. Accessed 10 Oct 2019

Federal Ministry for Sustainability and Tourism, Federal Ministry for Transport, Innovation and Technology (2018) \#mission 2030: Austrian Climate and Energy Strategy, Vienna. https://mission2030.info/ wp-content/uploads/2018/10/Klima-Energiestrategie_en.pdf. Accessed 18 March 2019

Intergovernmental Panel on Climate Change (2018) Global Warming of $1.5^{\circ} \mathrm{C}$ : An IPCC Special Report on the impacts of global warming of $1.5^{\circ} \mathrm{C}$ above pre-industrial levels and related global greenhouse gas emission pathways, in the context of strengthening the global response to the threat of climate change, sustainable development, and efforts to eradicate poverty. Summary for Policymakers. 
https://www.ipcc.ch/site/assets/uploads/sites/2/2018/07/SR15_SPM_version_stand_alone_LR.pdf. Accessed 15 March 2019

Jabareen YR (2006) Sustainable urban forms: their typologies, models, and concepts. J Plan Educ Res 26:38-52. https://doi.org/10.1177/0739456X05285119

Kretschmer F, Neugebauer G, Stoeglehner G, Ertl T (2018) Participation as a key aspect for establishing wastewater as a source of renewable energy. Energies 11:3232. https://doi.org/10.3390/en11113232

Lichtenegger K, Wöss D, Halmdienst C, Höftberger E, Schmidl C, Pröll T (2017) Intelligent heat networks: first results of an energy-information-cost-model. Sustain Energy Grids Netw 11:1-12. https ://doi.org/10.1016/j.segan.2017.05.001

Lichtenwoehrer P, Erker S, Zach F, Stoeglehner G (2019) Future compatibility of district heating in urban areas-a case study analysis in the context of integrated spatial and energy planning. JESS. https:// doi.org/10.1186/s13705-019-0192-5

Martinot E, McDoom O (2000) Promoting energy efficiency and renewable energy: GEF climate change projects and impacts. Global Environment Facility Facility, Whashington

Motzkus A-H (2002) Dezentrale Konzentration - Leitbild für eine Region der kurzen Wege? Auf der Suche nach einer verkehrssparsamen Siedlungsstruktur als Beitrag für eine nachhaltige Gestaltung des Mobilitätsgeschehens in der Metropolregion Rhein-Main. Geographisches Institut der Universität Bonn (Eds.) Bonner Geographische Abhandlungen 107. Asgard-Verlag: Sankt Augustin

Narodoslawsky M, Stoeglehner G (2010) Planning for local and regional energy strategies with the ecological footprint. J Environ Plan Policy Manag 12:363-379. https://doi.org/10.1080/15239 08X.2010.528885

Neugebauer G, Kretschmer F, Kollmann R, Narodoslawsky M, Ertl T, Stoeglehner G (2015) Mapping thermal energy resource potentials from wastewater treatment plants. Sustainability 7:12988-13010. https://doi.org/10.3390/su71012988

Newman P, Jennings I (2008) Cities as sustainable ecosystems. Principles and practices. Island Press, Washington

Ramirez Camargo L, Stoeglehner G (2018) Spatiotemporal modelling for integrated spatial and energy planning. Energy Sustain Soc 8:1189. https://doi.org/10.1186/s13705-018-0174-Z

Ramirez Camargo L, Zink R, Dorner W, Stoeglehner G (2015) Spatio-temporal modeling of roof-top photovoltaic panels for improved technical potential assessment and electricity peak load offsetting at the municipal scale. Comput Environ Urban Syst 52:58-69. https://doi.org/10.1016/j.compenvurb sys.2015.03.002

Register R (2002) Ecocites: building cities in balance with nature. Berkeley Hills Books, Berkeley

Stoeglehner G (2019) Conceptualizing quality in spatial planning. Spat Res Plan 77:1. https://doi. org/10.2478/rara-2019-0002

Stoeglehner G, Narodoslawsky M (2009) How sustainable are biofuels? Answers and further questions arising from an ecological footprint perspective. Bioresour Technol 100:3825-3830. https://doi. org/10.1016/j.biortech.2009.01.059

Stoeglehner G, Niemetz N, Kettl K-H (2011) Spatial dimensions of sustainable energy systems: new visions for integrated spatial and energy planning. Energy Sustain Soc 1:2. https://doi. org/10.1186/2192-0567-1-2

Stoeglehner G, Erker S, Neugebauer G (2014) Energieraumplanung: Ergebnisse der ÖREK-Partnerschaft: Materialienband. Schriftenreihe/Österreichische Raumordnungskonferenz (ÖROK), vol 192. Geschäftsstelle der Österr. Raumordnungskonferenz (ÖROK), Wien

Stoeglehner G, Neugebauer G, Erker S, Narodoslawsky M (2016) Integrated spatial and energy planning: Supporting climate protection and the energy turn with means of spatial planning. SpringerBriefs in applied sciences and technology. Springer, Cham

United Nations (n.y.) Sustainable development goals: knowledge platform. https://sustainabledevelopme nt.un.org. Accessed 12 March 2019

Van Nuffel L, Gorenstein Dedecca J, Smit T, Rademaekers K (2018) Sector coupling: how can it be enhanced in the EU to foster grid stability and decarbonise? Policy Department for Economic, Scientific and Quality of Life Policies Directorate-General for Internal Policies. European Parliament. http://www.europarl.europa.eu/RegData/etudes/STUD/2018/626091/IPOL_STU(2018)62609 1_EN.pdf Accessed 10 Oct 2019

Zach F, Erker S, Stoeglehner G (2019) Factors influencing the environmental and economic feasibility of district heating systemsa perspective from integrated spatial and energy planning. Energy Sustain Soc. https://doi.org/10.1186/s13705-019-0202-7 
Publisher's Note Springer Nature remains neutral with regard to jurisdictional claims in published maps and institutional affiliations. 